\title{
Implementation of Wavelet Packet Transform for Detection and Analysis of Stator Faults in Induction Machine
}

\author{
G. Rayappan', V. Duraisamy², D. Somasundareswari ${ }^{3}$, I. Rajarajeswari ${ }^{4}$ \\ ${ }^{1}$ Department of Electronics and Electronics Engineering, Adithya Institute of Technology, Coimbatore, India \\ ${ }^{2}$ Principal Maharaja Institute of Technology, Coimbatore, India \\ ${ }^{3}$ SriGuru Institute of Technology, Coimbatore, India \\ ${ }^{4}$ Department of Electrical \& Electronics Engineering, PPG Institute of Technology, Coimbatore, India \\ Email: rameshroyin@yahoo.co.in
}

Received 22 April 2016; accepted 10 May 2016; published 24 August 2016

Copyright (C) 2016 by authors and Scientific Research Publishing Inc.

This work is licensed under the Creative Commons Attribution International License (CC BY).

http://creativecommons.org/licenses/by/4.0/

(c) (i) Open Access

\begin{abstract}
Execution of an online detection technique for induction motor fault diagnosis and research at the current period of time is discussed in this paper. Wavelet packets transform (WPT)-based algorithm is used by the detection method for investigating and identification of many disruptions that happen in three-phase induction motors. The association of the coefficients of the WPT of line currents with the help of a main wavelet at the secondary level of resolution with a threshold discovered through an experiment at the time of the vital position can used to observe the motor reference point. The propagation of wavelet analysis and disintegration of the signal into an equivalent bandwidth which can attain a good disintegration of the solution than what wavelet analysis do is called as Wavelet packet analysis. In order to overcome accidental failing, the on-line fault diagnostics technology for the reduction of incipient errors is a must.
\end{abstract}

\section{Keywords}

Condition Monitoring, Fault Diagnosis, Induction Motor, Wavelet Packet Transform (WPT)

\section{Introduction}

Utmost extensively used mode of electrical device is because of its handiness and simple structure is Induction motors. Observing the quality of the motor is more necessary in order to find out any error occurred at the early stage. If errors are diagnosed, Faults can then be handled much before it totally affects the motor so that the sus- 
tenance price and shutdown time can be reduced. In order to sort out the initial motor faults, we require a humble technique to which we can rely on. Traditional induction machine condition monitoring methods [1] generally demand the help of sensors engrafted in the device to record variables like temperature or vibration [2]. Interrogation of final current waveforms [3] with the help of data collected below steady-state operating condition and can be used in appreciable concern in finding windings and other device errors. This may necessitate the deliberation of measures like input power [4] or negative sequence ingredient [5]. The identification of device errors with the help of information got at the time of speed transients [6] and the calculation of device parameters [7]-[11] are the latest vogue in condition monitoring. The almost generally described faults with $38 \%$ of all reported faults associates with stator [12]-[14] and Stator faults of induction motor. The utmost dominant and possibly corrosive in induction motor are Stator inter-turn faults. These faults get initiated as small shorts among a few turns in the similar winding which generate high current which results in serious decentralized rise in temperature and the defect progresses soon to a greater portion of the winding resulting in more increased destruction that might grow into a more serious turn-to-ground fault. Failure of the detachment among winding and ground can result in a greater ground current, which eventually cause impair the essence of the device irreversibly. High temperature, movement of laminations and coils are the many stresses that affect the performance of the stators. The above mentioned components generally extend to insulation failure and it gradually result in various kinds of stator faults. Conventional stator insulation failure security in industrial surroundings is done mainly by ground fault relays and negative-sequence or phase current balance relays. Instable line voltages negative-sequence relays still would engender nuisance trips. Early on fault detection aims [15] [16] will not be effectual for Ground fault relays. Identification of inter-turn fault in the stator winding is the major purpose of this study to propose an effective and unambiguous technique. Models are imitated with the help of the MATLAB SIMULINK and imitation conclusions are given. $1 \mathrm{HP}, 415 \mathrm{~V}, 3$ phase, $50 \mathrm{~Hz}$ induction motor is used in assessing it.

\section{Parameter Used for Fault Identification}

Parameters namely voltage, current, power and speed are used to identify the Faults in the motor. Monitoring the form of the motor can be done by estimating these parameters externally. The restrained electrical signal of an induction motor helps to protect machines from destructive currents and ground currents. So the present identification technique can be much readily instigated. Supply frequency is the sole ingredient of current withdrawn by a motor the generosity of the current Motor faults moderate to yield side bands. A portion of motor drive system is connected in prevailing voltage and current transducers by determining the present signal related with the current signal with the induction motor. As this is typical it is not necessary to be taken into the account at present. The much vastly used method to identify motor fault primarily is motor current signature research due to its ability to measure the mechanical and electrical faults with the help of the spectral essentials of the motor current signal. Next to that non-invasive technique I used. Motor current can be evaluated on-line hence causing on-line identification accomplishable.

\section{Methodology}

\section{A. Data acquisition}

The block diagram of the approach cast off for deducting the stator fault is displayed in Figure 1. A data acquisition block components are listed with the help of the current transformer where the current signal is evaluated. Wavelet packet transform analyzer for fault diagnosis is assimilated by current signal.

\section{B. WPT Analyzer}

The wavelet packet transform is the extensively utilized technique amid numerous signal dispensation approaches that were used for fault analysis. A windowing technique with inconstant size area is supported to accomplish the signal examination.WPT is used to examine the high frequency and also the low frequency data. The personal computer can be used to detect and recognize the sternness of the fault.

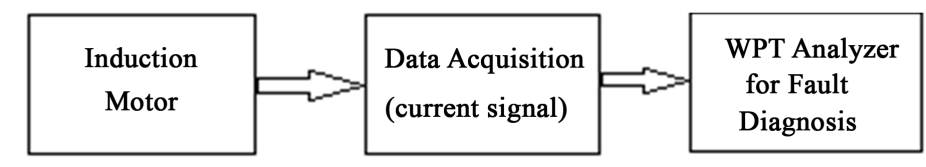

Figure 1. Block diagram. 


\section{Wavelet Packet Transform}

Wavelet Transform can be termed as a powerful signal processing technique which breaks the signal into packets called wavelets. These are scaled and shifted versions of mother wavelet. Besides, the scaling and shifting process produces time-scale representation of the signal. This offers resolution to low frequency components in addition to this, the high frequency components. WPT can be represented as a tree of low and high pass filters. A wavelet packet function $W_{j, k}^{n}(t)$ is a function with three indices: $j, k$, and $n$.

$$
W_{j, k}^{n}(t)=2^{j / 2} W^{n}\left(2^{j} t-k\right)
$$

Integer's $j$ and $k$ are indexes used for scale and translation operations respectively. The index $n$ is termed as the modulation parameter or oscillation parameter. The initial two-wavelet packet functions are the usual scaling function and the mother wavelet function. The procedure is initiated by passing the discrete signal $x[n]$ of length $N$ through a high pass filter with impulse response $h[n]$, and also through a low-pass filter with impulse response $g[n]$. The outputs of the high-pass and low-pass filters constitute a single level of decomposition of the discrete signal. The mathematical expression is given below:

$$
\begin{aligned}
d^{1}[n] & =\sum_{k=0}^{N-1} x[k] h[n-k] \\
a^{1}[n] & =\sum_{k=0}^{N-1} x[k] g[n-k]
\end{aligned}
$$

The outputs of high-pass and low-pass filters are $d^{1}[n]$ and $a^{1}[n]$, respectively. They represent the details $\left(d^{1}\right)$ and approximations $\left(a^{1}\right)$ of the original signal at level 1 . The signal at the first level is down sampled by two. This helps to achieve a better frequency resolution [17] [18]. Subsequent to the process of down sampling, each signal is further decomposed into low-pass and high-pass filters as shown in Figure 2. The main advantages of the WPT compared to other types of wavelet transforms are accurate and detailed representations of the decomposed signals.

\section{Feature Extraction}

In the proposed case, for fault diagnosis, a signature analysis method is used for feature extraction. The signals are decomposed up to the third level of resolution of the wavelet packet tree. This is done using the selected mother wavelet “db3”. The simulated results are used for analyzing the disturbances including fault currents. It is quite clear that the normal current does not have any high-or low-frequency components in the third-level details $\left(\mathrm{dd}^{3}\right)$ of the line current. When a disturbance occurs, the details $\left(\mathrm{dd}^{3}\right)$ shows high frequency components. This can be used as the feature extraction technique.

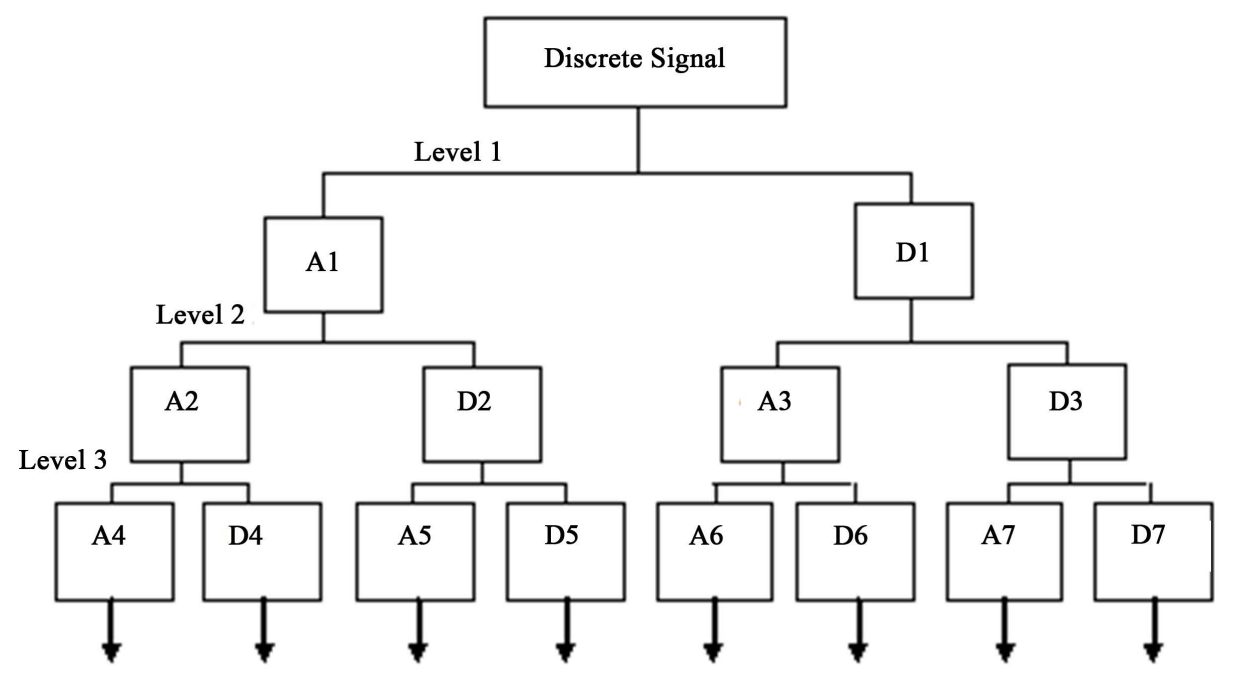

Figure 2. Three-level Decomposition of a discrete signal by WPT. 


\section{Experimental Setup}

The block diagram of the experimental setup is shown in Figure 3. It consists of a 5A current transformer. Here the primary is connected to one of the phases of the three phase input. The current transformer secondary is connected to a rheostat from which the electrical signal. This is further converted into sound signal by means of a sound chord. This sound signal is fed to a WPT analyzer for fault diagnosis in a Personal Computer. In the final stage, the stator condition is monitored. Figure 4 shows the actual hardware experimental setup in the laboratory.

\section{Simulation Result}

The simulations are done for the current signal obtained from a $1 \mathrm{HP}, 415 \mathrm{~V}, 50 \mathrm{~Hz}, 3$ Phase induction motor where the inter turn fault is created artificially by scratching the insulation of two adjacent turns.

In Figure 5 the induction motor current waveform in $\mathrm{db}$ is shown in its healthy condition. Figure 6 shows the faulty condition of the stator winding. Here disturbances are observed clearly from the amplitude.

Figure 7 and Figure 8 shows the third level high frequency details (dd3) of stator current for healthy and faulty motor. Using the simulated results analysis, the signatures of disturbances occurring during fault conditions is assessed.

$415 \mathrm{~V}, 50 \mathrm{~Hz}$ 3 Phase supply

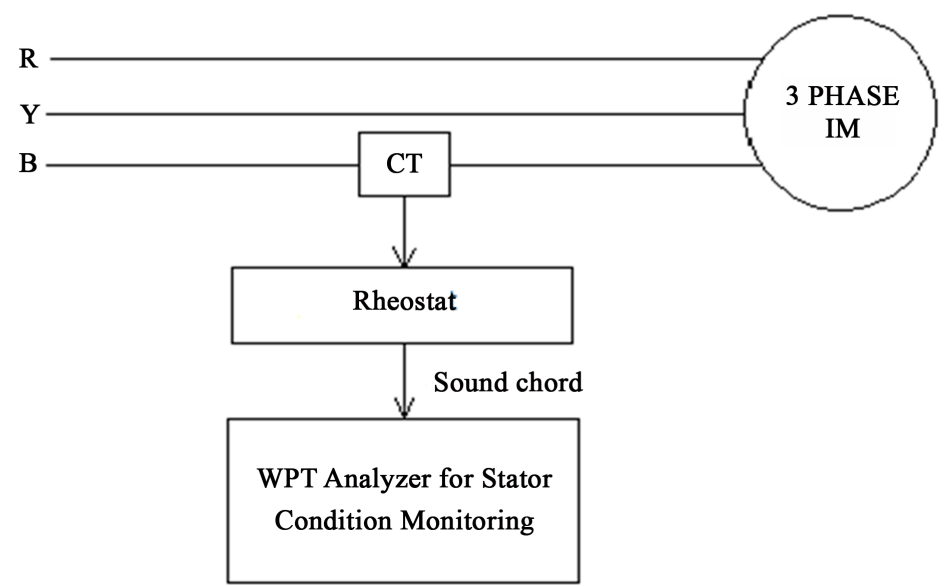

Figure 3. Block diagram of experimental setup.

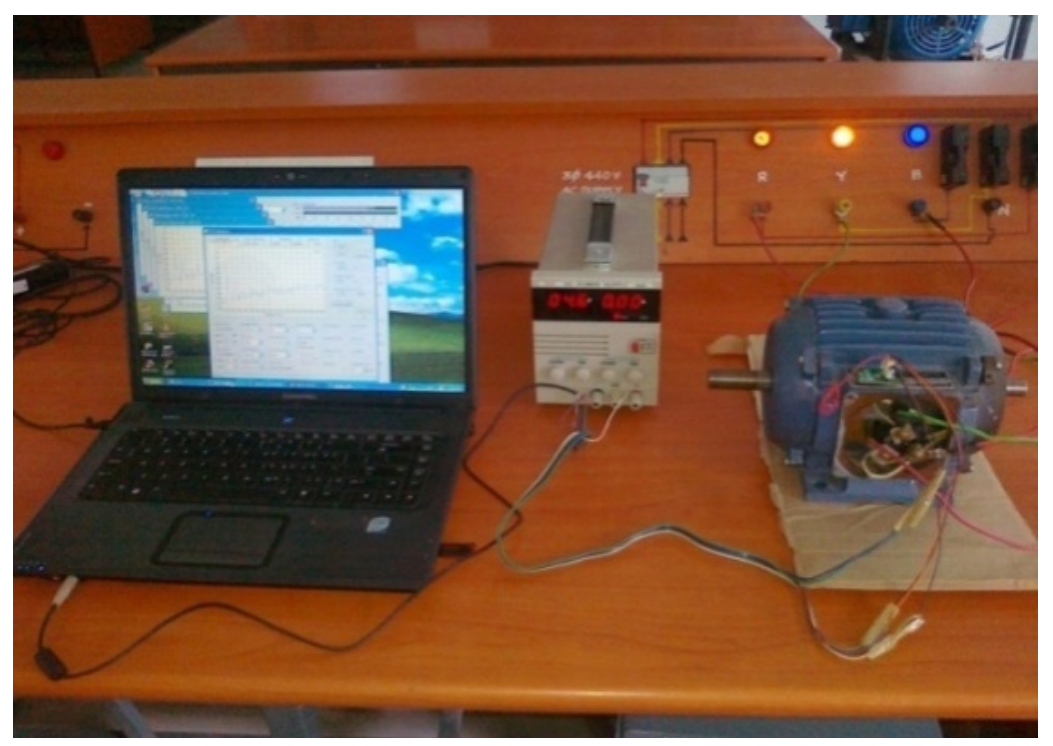

Figure 4. Experimental setup in laboratory. 


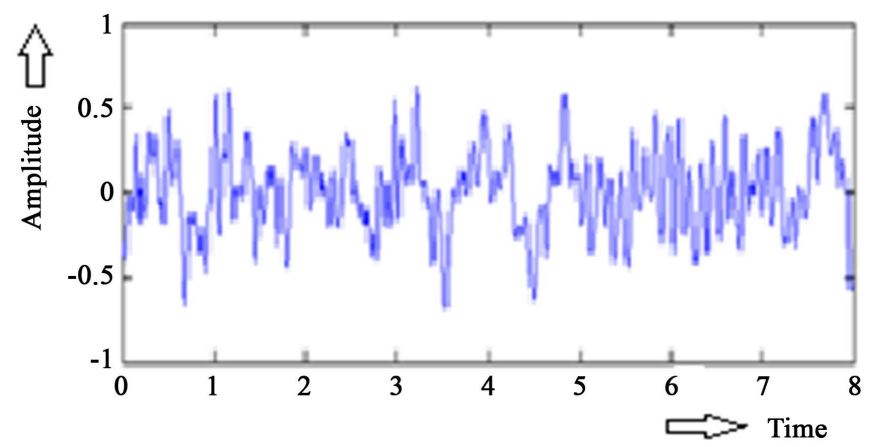

Figure 5. Simulated graph of healthy system in $\mathrm{db}$.

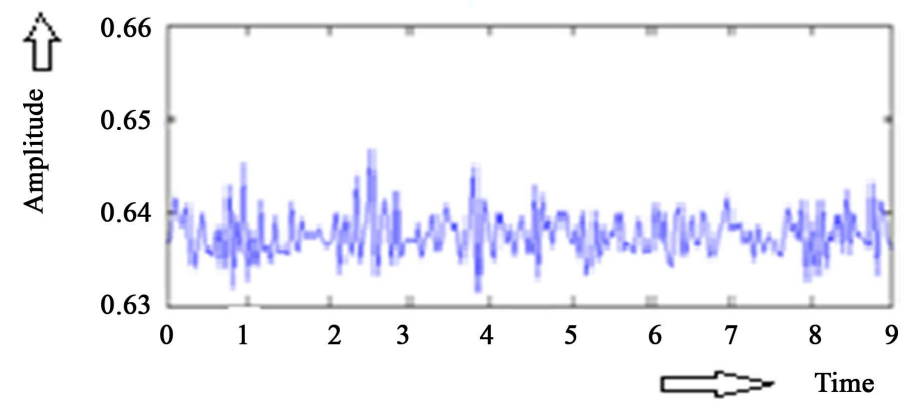

Figure 6. Simulated graph of faulty system in $\mathrm{db}$.

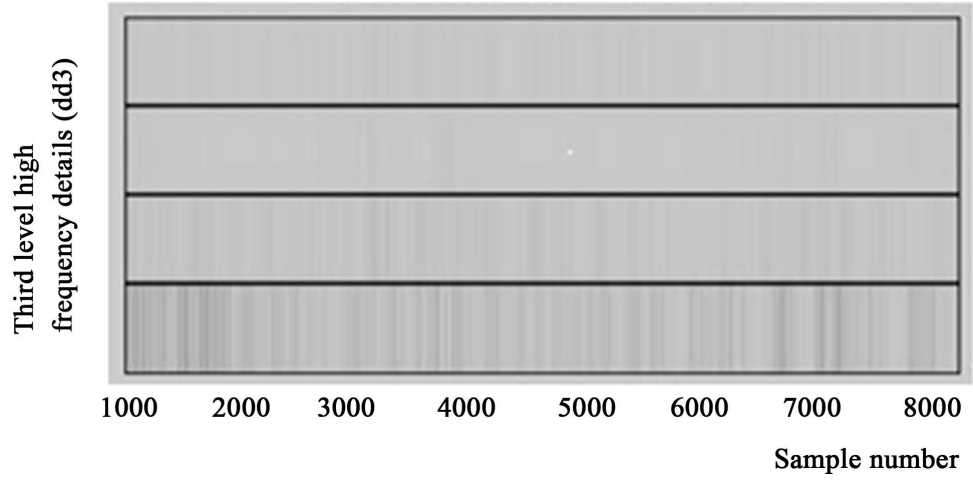

Figure 7. Third level high frequency details $\left(\mathrm{dd}^{3}\right)$ of stator current for healthy motor.

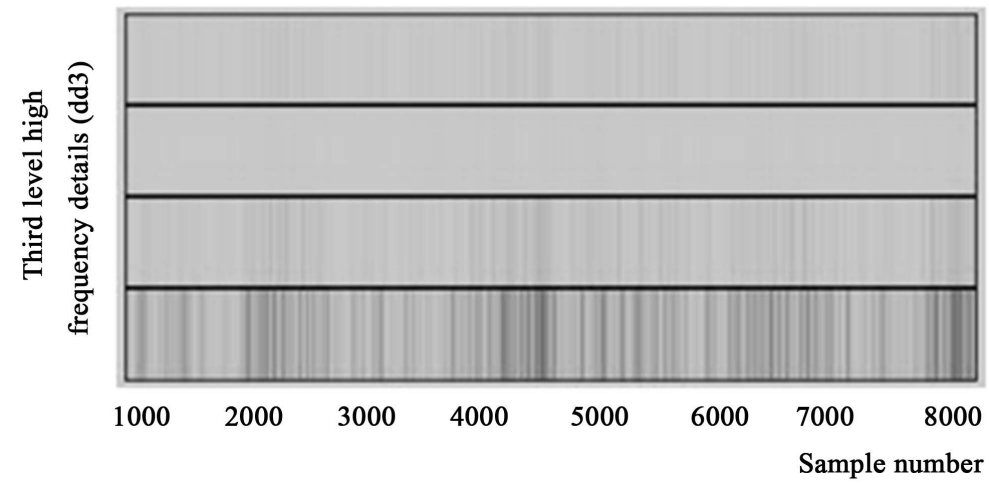

Figure 8. Third level high frequency details $\left(\mathrm{dd}^{3}\right)$ of stator current for faulty motor. 


\section{Conclusion}

This paper is a presentation of a WPT-based method for on-line condition monitoring of an induction motor. It can be implemented in real-time to detect stator inter-turn faults at a very earlier stage. WPT has the advantage of having better frequency resolution and localization. The proposed diagnosis technique identifies even a minute disturbance accurately and generates a trip signal almost instantly or within one cycle of the fault occurrence. Additionally, the detection technique does not issue any false trip signal during loaded or unloaded normal operating conditions. Thus the WPT-based detection scheme proves to be fast, accurate, and easy to implement in order to detect and provide correct diagnosis of changes in stator current amplitudes. This occurs as a result of different transient disturbances including faults in an induction motor.

\section{References}

[1] Tavner, P.J. and Penman, J. (1987) Condition Monitoring of Electrical Machines. Research Studies Press, Letchworth.

[2] Zhang, P., Du, Y., Habetler, T.G. and Lu, B. (2011) A Survey of Condition Monitoring and Protection Methods for Medium-Voltage Induction Motors. IEEE Transactions on Industry Applications, 47, 34-46. http://dx.doi.org/10.1109/TIA.2010.2090839

[3] Benbouzid, M.E.H. (2000) A Review of Induction Motors Signature Analysis as a Medium for Faults Detection. IEEE Transactions on Industrial Electronics, 47, 984-992. http://dx.doi.org/10.1109/41.873206

[4] Trzynadlowski, A.J. and Ritchie, E. (2000) Comparative Investigation of Diagnostic Media for Induction Motors: A Case of Rotor Cage Faults. IEEE Transactions on Industrial Electronics, 47, 1092-1099. http://dx.doi.org/10.1109/41.873218

[5] Trutt, F.C., Sottile, J. and Kohler, J.L. (2002) Online Condition Monitoring of Induction Motors. IEEE Transactions on Industry Applications, 38, 1627-1632. http://dx.doi.org/10.1109/TIA.2002.804758

[6] Douglas, H., Pillay, P. and Ziarani, A.K. (2005) Broken Rotor Bar Detection in Induction Machines with Transient Operating Speeds. IEEE Transactions on Energy Conversion, 20, 135-141. http://dx.doi.org/10.1109/TEC.2004.842394

[7] Said, M.S.N., Benbouzid, M.E.H. and Benchaib, A. (2000) Detection of Broken Bars in Induction Motors Using an Extended Kalman Filter for Rotor Resistance Sensorless Estimation. IEEE Transactions on Energy Conversion, 15, 6670. http://dx.doi.org/10.1109/60.849118

[8] Ethny, S., Acarnley, P.P., Zahawi, B. and Giaouris, D. (2006) Induction Machine Fault Identification Using Particle Swarm Algorithms. IEEE International Conference on Power Electronics, Drives and Energy Systems for Industrial Growth (PEDES 2006), New Delhi. http://dx.doi.org/10.1109/PEDES.2006.344310

[9] Ethni, S.A., Zahawi, B., Giaouris, D. and Acarnley, P.P. (2009) Comparison of Particle Swarm and Simulated Annealing Algorithms for Induction Motor Fault Identification. 7th IEEE International Conference on Industrial Informatics (INDIN 2009), Cardiff, June 2009, 470-474. http://dx.doi.org/10.1109/INDIN.2009.5195849

[10] Ethni, S.A., Gadoue, S. and Zahawi, B. (2014) Induction Machine Winding Faults Identification Using Bacterial Foraging Optimization. 7th IET International Conference on Power Electronics, Machines and Drives (PEMD), Manchester. http://dx.doi.org/10.1049/cp.2014.0298

[11] Alamyal, M., Gadoue, S.M. and Zahawi, B. (2013) Detection of Induction Machine Winding Faults Using Genetic Algorithm. 9th IEEE International Symposium on Diagnostics for Electric Machines, Power Electronics and Drives (SDEMPED 2013), Valencia, August 2013, 157-161. http://dx.doi.org/10.1109/DEMPED.2013.6645711

[12] Albrecht, P.F., Appiarius, J.C., McCoy, R.M., Owen, E.L. and Sharma, D.K. (1986) Assessment of the Reliability of Motors in Utility Applications-Updated. IEEE Transactions on Energy Conversion, 1, 39-46. http://dx.doi.org/10.1109/TEC.1986.4765668

[13] Report of Large Motor Reliability Survey of Industrial and Commercial Installations, Part II. IEEE Transactions on Industry Applications, 21, 865-872.

[14] Singh, G.K. and Al Kazzaz, S.A.S. (2003) Induction Machine Drive Condition Monitoring and Diagnostic ResearchA Survey. Electric Power Systems Research, 64, 145-158. http://dx.doi.org/10.1016/S0378-7796(02)00172-4

[15] Tallam, R.M., Lee, S.B., Stone, G., Kliman, G.B., Yoo, J., Habetler, T.G. and Harley, R.G. (2003) A Survey of Methods for Detection of Stator Related Faults in Induction Machines. IEEE International Symposium of Diagnostics for Electric Machines, Power Electronics and Drives, 1, 35-46. http://dx.doi.org/10.1109/demped.2003.1234544

[16] Tallam, R.M., Lee, S.B., Stone, G.C., Kliman, G.B., Yoo, J., Habetler, T.G. and Harley, R.G. (2007) A Survey of Methods for Detection of Stator-Related Faults in Induction Machines. IEEE Transactions on Industry Applications, 43, 920-933. http://dx.doi.org/10.1109/TIA.2007.900448 
[17] Yen, G.G. and Lin, K.C. (2000) Wavelet Packet Feature Extraction for Vibration Monitoring. IEEE Transactions on Industrial Electronics, 47, 650-667. http://dx.doi.org/10.1109/41.847906

[18] Khan, M.A.S.K. (2007) Real-Time Implementation of Wavelet Packet Transform-Based Diagnosis and Protection of Three-Phase Induction Motor. IEEE Transactions on Energy Conversion, 22.

Submit or recommend next manuscript to SCIRP and we will provide best service for you:

Accepting pre-submission inquiries through Email, Facebook, LinkedIn, Twitter, etc.

A wide selection of journals (inclusive of 9 subjects, more than 200 journals)

Providing 24-hour high-quality service

User-friendly online submission system

Fair and swift peer-review system

Efficient typesetting and proofreading procedure

Display of the result of downloads and visits, as well as the number of cited articles

Maximum dissemination of your research work

Submit your manuscript at: http://papersubmission.scirp.org/ 